\title{
ERRÂNCIAS NO ESPAÇO PÚBLICO: RECURSOS PARA AS DISCIPLINAS DE PROJETO
}

María Cristina Ibarra

Escola Superior de Desenho Industrial

Universidade do Estado do Rio de Janeiro

mariacih@gmail.com

Resumo: As cidades estão cheias de 'desvios'. Se olharmos pela janela, ou melhor, se dermos um passeio pelas ruas detidamente, perceberemos que as pessoas e o uso que dão ao espaço público são mais fortes do que é planejado. Vários autores falam desta força que existe nos que experimentam diariamente a cidade. No seguinte artigo, pretende-se fazer uma breve reflexão sobre este tema passando pelo pensamento destes autores, mostrar uma pequena intervenção que foi feita Rio de Janeiro com a turma da disciplina 'Design e Cidade' do PPESDI da ESDI/UERJ no segundo semestre de 2015, e refletir sobre como essa capacidade criativa pode virar recurso para as disciplinas de projeto.

Palavras-chave: errâncias, urbanismo, design.

\begin{abstract}
Cities are full of 'deviations'. If we look out the window, or better, if we carefully take a stroll through the streets, we realize that people and use that they give to the public space are stronger than what is planned. Several authors speak of this force that exists in daily experience the city. In the following article, we intend to make a brief reflection on this issue through the thought of these authors, show a small intervention that was made in Rio de Janeiro streets with the class of the subject 'Design and the City' of PPESDI of ESDI / UERJ in second half of 2015 and reflect on how this creativity can become resource for design disciplines.
\end{abstract}

Keywords: wanderings, urbanism, design 


\title{
1. INTRODUÇÃO
}

As cidades estão cheias de 'desvios'. Se olharmos pela janela, ou melhor se dermos um passeio pelas ruas detidamente, perceberemos que as pessoas e o uso que dão ao espaço público, são mais fortes do que é planejado. Como fala Paola Berenstein, "os urbanistas indicam usos possíveis para o espaço projetado, mas são aqueles que o experimentam no cotidiano que os atualizam" (JACQUES, 2008, p.53). Quer dizer que geralmente o plano do espaço projetado sofre desvios através do uso que lhe dão os cidadãos no dia a dia.

Vários autores falam desta força que existe nos que experimentam diariamente a cidade. No seguinte artigo, pretende-se fazer uma breve reflexão sobre este tema passando sobre o pensamento de alguns autores, mostrar uma pequena intervenção que foi feita nas ruas do Rio de Janeiro com a turma da disciplina 'Design e Cidade' do PPESDI da ESDI/UERJ no segundo semestre de 2015, e refletir sobre como essa capacidade criativa pode virar recurso para as disciplinas de projeto. Para isto começo por um pequeno mapeamento de alguns pensadores sobre o tema, narro nossa experiência de intervenção no espaço público e faço uma análise sobre o que fazer com essas errâncias suportada por alguns casos.

\section{MAPEAMENTO}

Antonio Negri, falando sobre Rem Koolhas e seu livro Delirious New York indica que a tese central desse livro consistia em:

\begin{abstract}
Dar uma imagem da metrópole que, além e através das planificações [...] vivia, porém, de dinâmicas, conflitos e sobreposições potentes de estratos culturais, de formas e de estilos de vida, de uma multiplicidade de hipóteses e de projetos sobre o futuro. Era necessário olhar esta complexidade, esta microfísica de potências, desde dentro para compreender a cidade. Nova York, em especial, era o exemplo de um extraordinário acumular-se histórico e político, tecnológico e artístico, de várias formas de programação urbana. Mas não bastava. Era necessário acrescentar que a metrópole era mais forte que o urbano. Os interesses especulativos e as resistências dos cidadãos derrotavam e subvertiam ao mesmo tempo as prescrições do poder e as utopias dos opositores. (NEGRI, 2008, p. 202)
\end{abstract}

Negri ressalta do livro de Koolhas que Nova York como metrópole vivia além e através das planificações, mas também de uma multiplicidade de formas, de estilos de vida, de hipóteses e projetos para o futuro, e que para entender a cidade tinha que se olhar esta complexidade. Sabendo que "a metrópole era mais forte que o urbano", entende-se que os cidadãos derrotavam esses planejamentos e que eles eram mais fortes do que as várias formas de programação urbana.

Continuando o mesmo pensamento, no livro 'Elogio aos Errantes', Paola Berenstein fala da experiência errática na cidade. Diz que "as errâncias são um tipo de experiência não planejada, desviatória dos espaços urbanos, são usos conflituosos e dissenssuais que contrariam ou profanam [...] os usos que foram planejados" (JACQUES, 2014, p. 31). Segundo ela, estamos vivendo hoje um processo de espetacularização das cidades e de redução da experiência onde cada vez mais esta é domesticada e os espaços públicos são pacificados, esterilizando a esfera pública, ou 
seja, a experiência de alteridade, do Outro nas cidades. Esse outro urbano, chamado assim pela autora, é aquele que resiste à anestesia pacificadora, que inventa, reinventa seu cotidiano, e que ocupa o espaço público. Ele se torna explícito nos que vivem nas ruas - moradores de rua, ambulantes, camelôs, catadores, prostitutas, entre outrospessoas que a maioria prefere manter na invisibilidade e que são os alvos mais comuns dos projetos urbanos espetaculares, pacificadores, os chamados revitalizadores.

Os errantes são, segundo a autora, os que realizam errâncias urbanas, ou seja, resistências ou insurgências contra a ideia de empobrecimento que nasce a partir da modernidade. Ela assinala que estas errâncias são críticas ao urbanismo e que elas legitimam aquilo que foi projetado, pois são "essas experiências do espaço pelos habitantes, passantes ou errantes que reinventam esses espaços no seu cotidiano" (JACQUES, 2008). Para Berenstein o urbanismo nasceu para modernizar as cidades, ou seja, para transformar as cidades coloniais (no Brasil) e as cidades medievais (na Europa) em metrópoles modernas. Igualmente para Lúcio Costa, segundo Lauro Cavalcanti (1999), e para outros modernistas, o urbanismo e a arquitetura eram "vistos como meios para realizar o sonho de um domínio racional do futuro em substituição ao caos das cidades capitalistas" (CAVALCANTI, 1999, p.55). As errâncias são críticas ao urbanismo e também à modernidade, e portanto ao domínio racional do futuro.

O melhor exemplo de modernidade no Brasil é sua capital, Brasília. Várias foram (ou são) as errâncias e portanto, legitimações presentes por parte das pessoas que experimentam a cidade depois da sua inauguração em 1960. Segundo Lauro Cavalcanti (1998), Brasília nasceu com o intuito de ajudar ao desenvolvimento do interior do país dando-lhe importância política. Assim, foi aberto um concurso para a escolha do plano urbanístico cujo vencedor foi Lúcio Costa. Com este projeto, segundo este autor, a rua desapareceu e, portanto, a figura do pedestre; foram criadas superquadras de 240 por 240 metros compostas por blocos de apartamentos e junto com outras superquadras e estabelecimentos para o comércio, serviços e clubes formavam as vizinhanças. Os apartamentos, de propriedade pública, foram distribuídos para pessoas de diferentes camadas sociais, com o objetivo de alterar a sociedade e promover o exemplo de novas formas de organização. Os prédios estatais foram marcados pela monumentalidade, pois a nova capital devia ter um elemento que a distinguisse de outras cidades do interior. Mas com a experiência das pessoas na cidade houve alguns desvios do plano. $\mathrm{O}$ autor assinala vários.

Primeiro o erro de previsão em relação às moradias dos operários que trabalharam na construção da cidade. Segundo os planos, na cidade permaneceriam um terço dos operários que seriam localizados no setor dos serviços, o outro terço trabalharia em labores agrícolas para abastecer a cidade, e o outro voltaria para suas cidades de origem. Aconteceu que praticamente nenhum operário decidiu abandonar a nova capital e daí surgiram as cidades-satélites, que eram em princípio acampamento de excluídos, como as favelas, e que depois foram legalizadas pelo governo. Segundo, a ideia de juntar pessoas de diferentes camadas sociais não funcionou devido à grande hierarquia existente dentro das entidades públicas. Também a população do plano piloto, majoritariamente vinda do Rio de Janeiro, não se acostumou com a ideia da eliminação das ruas e dos lugares espontâneos de convívio, ocasionando assim a recriação da rua.

Além disso, os espaços de convivência na cidade só propiciam a integração de iguais, tornando-se segundo o autor, uma das cidades mais segregadoras do país. 
Também é um pouco incoerente que querendo que fosse o centro político nacional e a cidade do futuro, Brasília seja apreciada por seus atributos bucólicos. Ainda no tempo quando o ator escreveu o artigo muitos dos órgãos políticos funcionavam desde o Rio de Janeiro. A nova capital virou uma cidade transitória na qual os diferentes funcionários viajam todos os fins de semana para suas respectivas cidades. $O$ autor termina o artigo falando que "o tempo se encarregou de quebrar a onipotência 'moderna' de alterar a sociedade através da arquitetura e do urbanismo, do mesmo modo que indica terem os modernistas criado um dos mais consistentes estilos de nossa história arquitetônica" (CAVALCANTI, 1998, p. 61). Como vemos, apesar do grande plano e a grande vontade de mudar a sociedade, a complexidade que há dentro dos múltiplos estilos de vida que uma cidade pode ter é muito maior do que as planificações urbanas. Os desvios que sofreu o plano a partir da vivência dos cidadãos derrotaram a ideia modernista de espetacularização dos espaços, e do empobrecimento da experiência no espaço público. Brasília é um claro exemplo disso.

\section{EXPERIÊNCIA}

Ao final do semestre da disciplina 'Design e Cidade' do PPDESDI da Escola Superior de Desenho Industrial ESDI/UERJ, as professoras Bárbara Szaniecki e Clarissa Moreira, e Talita Tibola propuseram fazer uma deriva com a turma (12 alunos) pelo centro do Rio de Janeiro. Entenda-se deriva como a define Paola Berenstein: "um tipo específico de errância urbana, uma apropriação do espaço urbano pelo vivenciador através da ação do andar sem rumo". (JACQUES, 2014, p. 221). Várias ideias surgiram na aula, entre essas a minha proposta de fazer uma pequena intervenção nos arredores da ESDI. Esta ideia surgiu depois de conhecer os trabalhos do coletivo Poro de Belo Horizonte (CAMPBELL, 2011) e de ler o livro Guerrila Art Kit da artista canadense Keri Smith (2008). Para ela o Guerrilla Art (ou Arte de Guerillha em português) consiste em qualquer trabalho anônimo instalado, representado ou colado em espaços públicos com o claro propósito de afetar o mundo em uma maneira criativa ou que provoque pensamentos. (SMITH, 2008)

A intervenção tinha como objetivo fazer um pequeno mapeamento de situações no espaço urbano que mostrassem evidencia de um errar pela cidade. Após várias leituras sobre o tema considerei necessário buscar no espaço público casos concretos (artefatos ou situações) que escapassem no dia a dia à ideia de projeto. Assim, a intervenção ou arte de guerrilha, como é chamado por Smith (2007), consistia em colar um adesivo com a frase "Aqui esta/este foi usado (a) para " (FIG. 1), em lugares onde encontrássemos evidencia de casos de pessoas que deram um novo uso para um espaço e/ou coisa. 


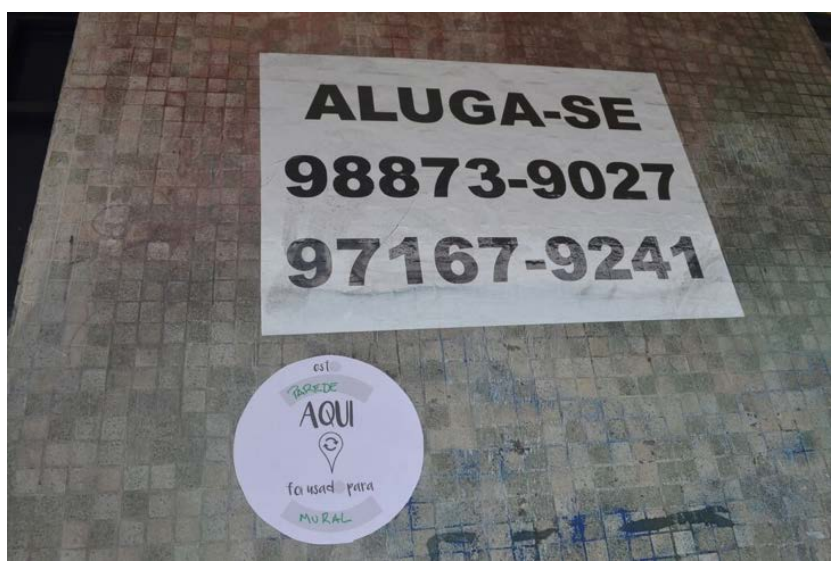

Figura 1 - Adesivo “Aqui esta/este foi usado(a) para " Foto da autora.

Para a atividade usamos: o adesivo, canetas, máquina fotográfica, e um mapa da zona. Apesar (apesar da ideia ter começado) em forma de deriva, preparamos um caminho devido à outra atividade que foi realizada de forma paralela. Começamos na ESDI, seguimos em direção à rua Evaristo da Veiga, viramos na Rua das Marrecas, prosseguimos pela Rua do Passeio, viramos à esquerda pela Rua Senador Dantas e subimos até a Cinelândia pela Rua Embaixador Régis de Oliveira. O mapa da Figura 2 mostra o percurso e os lugares onde foram encontrados cada caso.

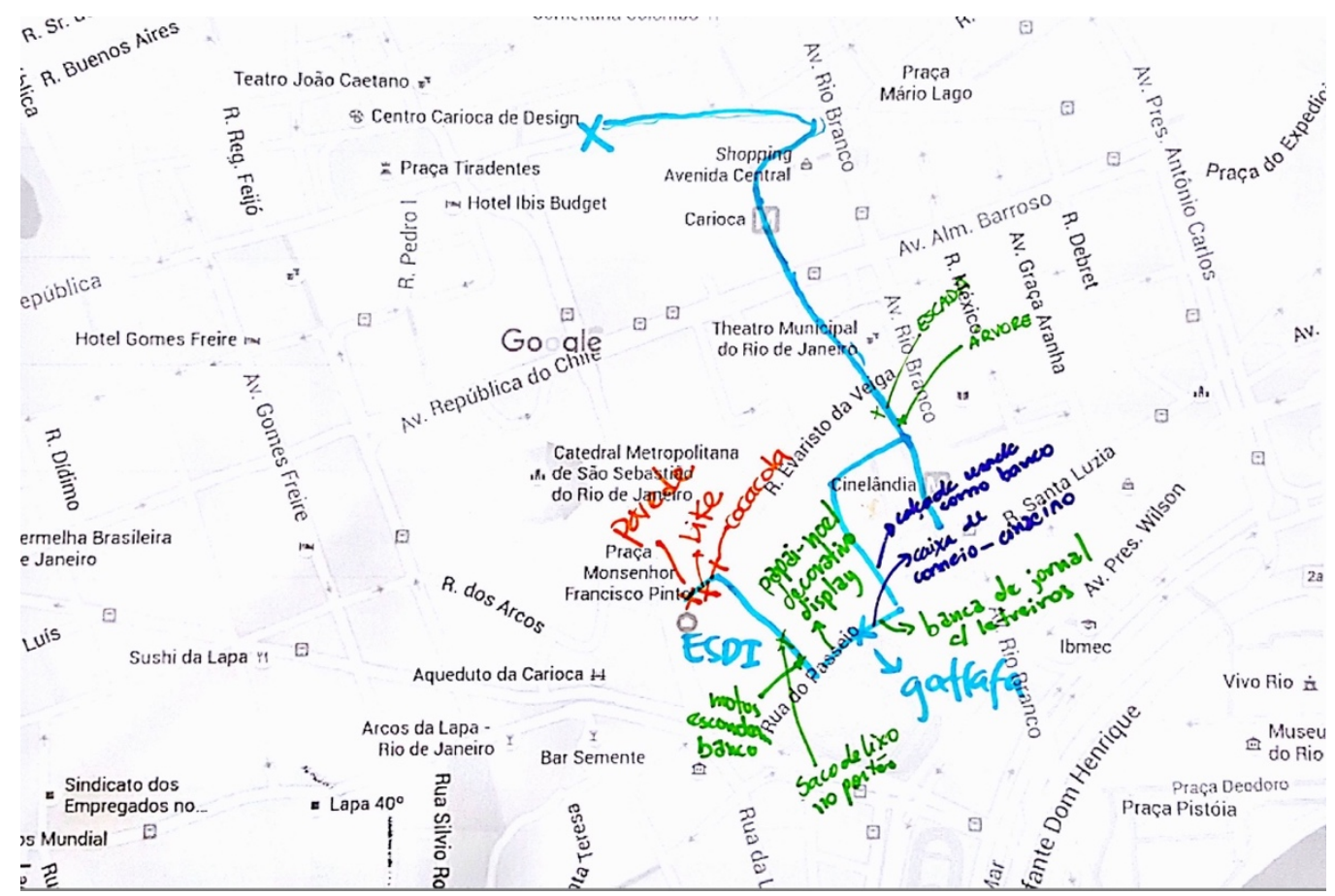

Figura 2 - Percurso realizado e lugares onde foram encontrados cada caso.

Elaborado pela autora, com base na pesquisa realizada

Foram encontrados vários: "Esta praça foi usada como palco", "Este garrafão foi usado para sentar", "Este poste foi usado para atar o guarda-sol", "Estas motos foram usadas para camuflar o banquinho", "Este cano foi usado para segurar a bicicleta", "Esta caixa de correio foi usada para apagar o cigarro", "Esta gola de árvore 
foi usada para sentar", "Este orelhão foi usado para jogar lixo", "Esta parede foi usada como mural", "Esta caixa foi usada para evitar que estacionem", "Este portão foi usado para pendurar o lixo", "Este anúncio foi usado como espelho", "Estes copos foram usados para guardar os resultados do jogo do bicho", "Este papelão foi usado como tapete", (FIG. 3)

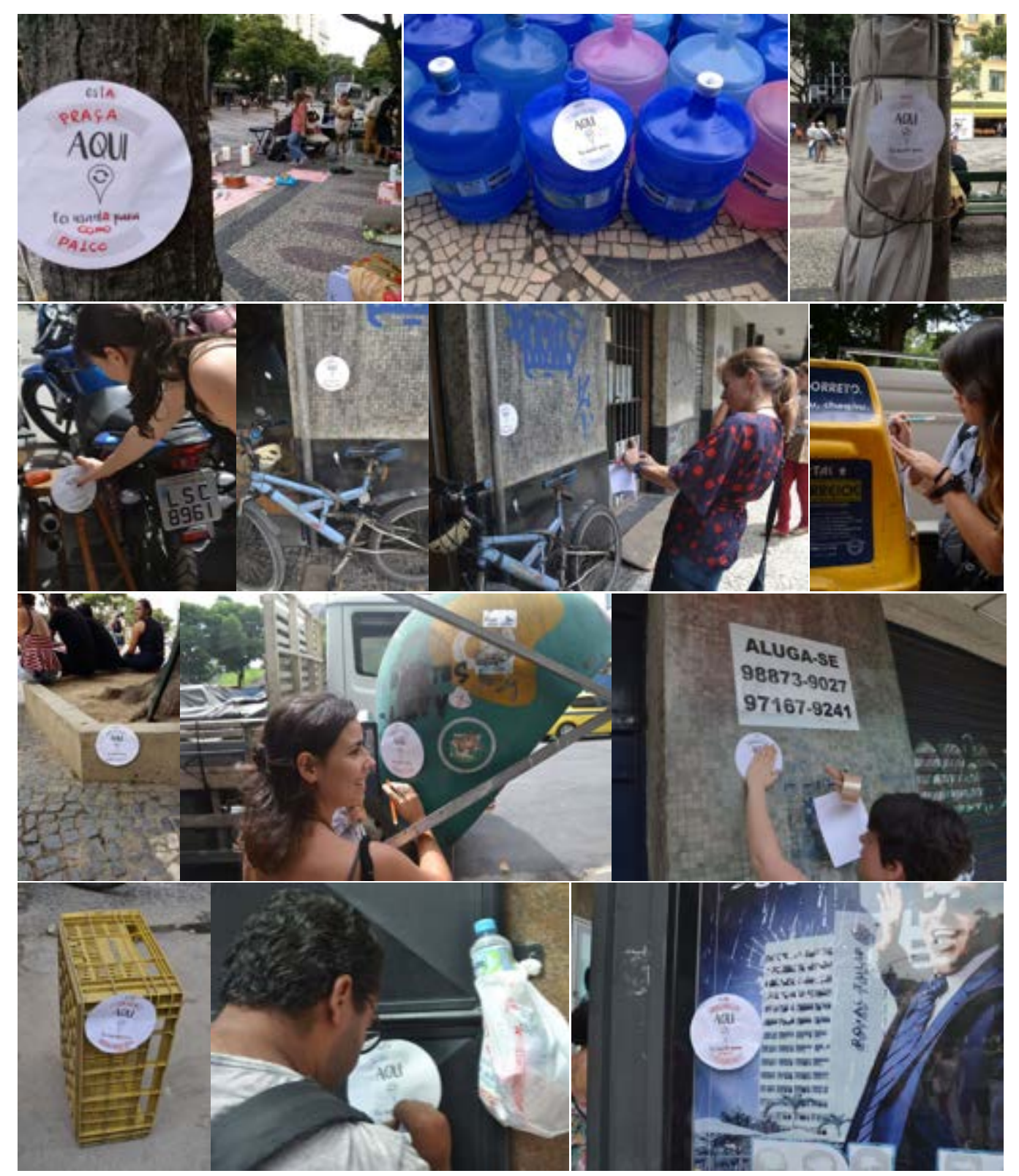

Figura 3 - Casos encontrados.

Fotos de: Marilane Abreu, Ana Dias, Talita Tibola e Maria Cristina Ibarra

A turma encontrou diferentes casos, que organizei por semelhança em 6 grupos. O primeiro está relacionado com colar, pendurar, segurar, atar, guardar. 0 segundo, com descansar. O terceiro com jogar lixo, o quarto com evitar ou camuflar, o quinto com olhar-se, e o sexto com representar. (FIG. 4) 


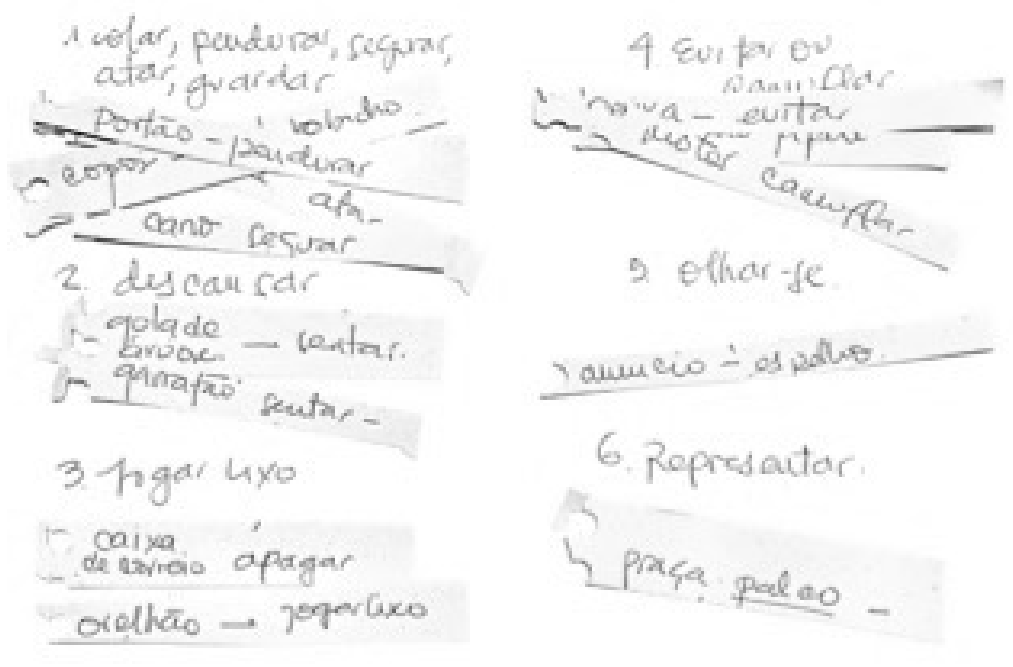

Figura 4 - Organização dos casos por grupos

Elaborado pela autora, com base na pesquisa realizada

Como vemos cada situação e/ou objeto encontrado no caminho mostra que foi utilizado para um fim que não foi planejado. Ou seja, os outros usos que são dados a estes artefatos encontrados no espaço público evadem os usos que foram traçados inicialmente. As pessoas nas ruas se apropriam dos espaços e coisas e viram errantes, inventando e reinventando seus cotidianos, legitimando e atualizando assim aquilo que foi projetado. Estes exemplos evidenciam ações dos cidadãos que resistem às tentativas pacificadoras do urbano, pois vivem a experiência de alteridade. São errantes.

Com a atividade tivemos a oportunidade de olhar o espaço público de uma maneira diferente, de nos comportar também como errantes, deixar uma evidência (o adesivo) com a expectativa de que outras pessoas pudessem se dar conta de que o espaço público pode se usar de outra maneira, de que as pessoas o usam de maneiras diferentes, e de fazer uma narração. A professora 1 sugeriu que no adesivo colocássemos uma carinha sorrindo para mostrar que o que estávamos fazendo não era penalizando este tipo de ações, senão lhes fazendo um pequeno reconhecimento. Com o exercício evidenciou-se que no centro do Rio de Janeiro existem casos de errantes. $\mathrm{O}$ que fazer com isso?

\section{O QUE FAZER COM AS ERRÂNCIAS?}

Com a experiência é evidente que há uma força criativa nas pessoas que vivem a metrópole. O que fazer com ela? Como incentivar as errâncias? No trabalho de Hélio Oiticica podemos ver que, por exemplo, a arquitetura das favelas foi determinante na criação dos parangolés.

Paola Berenstein (2007) explica muito bem seu trabalho no livro a 'Estética da Ginga'. Segundo a autora, nas favelas, os barracos são construídos juntando diferentes materiais que os favelados encontram na cidade. Uns dos primeiros passos da construção consiste em instalar uma estrutura de sustentação onde se pregarão latões aplainados, pedaços de madeira e mesmo de papelão. Estes fragmentos são substituídos à medida que o favelado vai encontrando outros materiais e à medida que a chuva os vai deteriorando. $\mathrm{O}$ aspecto fragmentário das favelas vai mudando com o 
tempo, mas os barracos, e consequentemente a própria favela jamais ficam de todo concluídas. A autora continua dizendo que nunca há projeto preliminar para um barraco, pois o processo todo vai depender dos achados de sobras interessantes, e que esta maneira de viver se aproxima mais da ideia de abrigar que de habitar. Já que o abrigar faz parte do temporário e provisório e habitar é da ordem do durável e permanente.

A arquitetura das favelas é essencial no trabalho do artista carioca Hélio Oiticica. Sua vivência no morro da Mangueira influiu completamente na sua obra. Ele disse: "a experiência com a dança (o samba) deu-me, portanto, a exata ideia do que seja criação pelo ato corporal, a contínua transformalidade". (OITICICA apud JACQUES, 2007, p. 31). Jacques (2003) aponta que no parangolé os movimentos do corpo que dança se transformam continuamente como as fachadas dos abrigos das favelas, utilizando a mesma ideia do estar temporário, do estar em transformação, do tornarse. A música e a percussão também são improvisadas e a obra é inacabada e aberta, pois o espectador passa a ser participante tornando-se coautor, colocando em questão a noção de autor. Oiticica chegou a propor, segundo a autora, que os materiais fossem dados aos participantes para que eles pudessem produzir suas próprias obras. Ela continua dizendo que:

Oiticica compreendeu muito bem seus princípios construtivos (das favelas); apropriou-se da concepção e dos materiais de construção dos barracos, sem, no entanto, copiá-los formalmente [...] os parangoles não são ilustrações dos abrigos das favelas (mimese), eles certamente se inspiram nesses abrigos, mas não de modo simplista e formal. (JACQUES, 2003, p. 32)

O trabalho de Oiticica vai além da forma e portanto, da superficialidade. Ele traspassa a maneira modernista de fazer as coisas, indo para um plano muito mais ligado à coletividade e à capacidade criativa do ser humano, colocando o espectador como co-autor da obra e utilizando conceitos que desde fora podem ser vistos como problemas (como é o caso da temporalidade e a transformação), em forma de oportunidades. Isto foi atingido devido à sua experiência direta com a comunidade. Hélio Oiticica, disse a autora: "viveu na Mangueira, na sua escola de samba, experimentou essa favela, vivenciou-a. Reproduziu subjetivamente em seu trabalho de artista sua experiência de vida no morro, que é diferente daqueles que lá vivem, por nunca ter sido um verdadeiro favelado". (JACQUES, 2008, p. 36)

Os parangolés foram mostrados ao público em 1965. Este é um caso onde a capacidade criativa das pessoas, dos errantes, das favelas é utilizada como inspiração para uma obra de arte, não só desde a forma, mas desde seus princípios e dinâmicas, e também onde a sua autoria é colocada em questão por ser feita na coletividade e não especificamente pelo artista.

Por outra parte, desde o ponto de vista do design, Aloísio Magalhães falando sobre cultura e desenvolvimento propôs no 1ㅇ Seminário Interamericano sobre Políticas Culturais e Desenvolvimento, realizado no Colorado que no futuro próximo fosse estimulada a invenção do objeto nascida da necessidade de supervivência (sobrevivência), e não só a produção inicial. Ele apontou, segundo um artigo escrito por Beatriz Schiller para o Jornal do Brasil originalmente publicado em 1978, que no Nordeste do país as pessoas desenvolveram uma tecnologia complicada para abrir um pneumático: estendê-lo e, usando técnicas de artesanato de couro, criaram latas de 
lixo que são fortes, inquebráveis, baratas e sem anúncios, distribuição ou estímulo de qualquer ordem. Disse que o $82 \%$ dos lares do Nordeste tem essas lixeiras, e que como estímulo poderiam ser importadas antes que alguém de outro país as industrialize.

Seguido deste exemplo colocou um cenário duplo: São Paulo/Triunfo. São Paulo, um importante centro econômico, e Triunfo, uma pequena cidade do Nordeste de possibilidades limitadas. Com isto, diz a autora, se situam os diversos "desenvolvimentos" no Brasil. São Paulo por uma parte produzindo pneumáticos e o Triunfo fazendo latas de lixo de pneumáticos velhos. O que é desenvolvimento, perguntou-se Aloísio, "é continuarmos encorajando megalópoles, como São Paulo, ou é repensarmos, buscando outros Triunfos com possiblidades mais amplas? ". (SCHILLER, 1978, p. 95)

A pesar do que acontece com as latas de lixo no Nordeste não faz parte de um desvio no planejamento urbano, o exemplo mostra a capacidade criativa dos nãodesigners. Estas pessoas não desviam um plano urbano, mas dão outros usos a uma coisa que inicialmente não foi projetada para isso: os pneumáticos. O que propõe Aloísio é um desenvolvimento que leve em conta a população local e que aumente as possibilidades das comunidades a partir dos recursos com os quais elas contam.

Podemos ver tanto no caso da obra de Hélio Oiticica e no caso das latas de lixo do Triunfo que a figura do autor passa a um segundo plano, dando maior importância ao fazer das pessoas. No Chile, o arquiteto Alejandro Aravena, ganhador do prêmio Pritzker 2016 fez um projeto com estes mesmos princípios (Aravena, 2014). Na apresentação que fez para TED em 2014, o arquiteto conta que foram convidados a acomodar 100 famílias que estavam ocupando de forma ilegal meio hectar no centro de lquique, uma cidade ao norte do país, usando um subsídio de 10 mil dólares com o qual tinham que comprar o terreno, fornecer a infraestrutura, e construir as casas. Em um processo de design participativo entenderam que as famílias não queriam morar em edifícios e tinham pouco dinheiro para comprar o terreno que era 3 vezes maior do que a habitação social normalmente pode pagar, portanto, encontravam-se diante de um problema.

Ele disse que uma família de classe média vive razoavelmente bem em uma casa de $80 \mathrm{~m}^{2}$, mas quando não há dinheiro a solução é reduzir a casa para $40 \mathrm{~m}^{2}$. A proposta que fizeram foi construir a metade de uma casa de $80 \mathrm{~m}^{2}$, para não construir uma casa pequena de $40 \mathrm{~m}^{2}$. Ou seja, como disse o arquiteto, a solução encontrada foi o ponto meio entre uma casa e um prédio, podendo ter possiblidades de expansão. Finalmente, as unidades ficaram como casas de classe média em parte construídas pelas próprias famílias em algumas semanas. Ou seja, como disse o arquiteto, a resposta estava nas próprias favelas (ARAVENA, 2014). Parte da solução do problema, estava no próprio problema. É importante usar a capacidade criativa dos errantes para legitimar a priori o que seria legitimado da mesma maneira em outras circunstâncias e criar soluções que fiquem mais perto do que as pessoas esperam.

\section{CONSIDERAÇÕES FINAIS}

Com este caso podemos ver que desde a arquitetura pode-se aproveitar das pessoas que não são treinadas na área a capacidade criativa que permite as errâncias. Vemos nestes 3 casos que o cidadão se faz presente na obra e que desta maneira se questionam alguns preceitos da arte, do design e da arquitetura como disciplinas. Por que não envolver as pessoas dentro do processo de criação? Vários são os métodos 
que as disciplinas de projeto têm buscado para chegar a soluções que fechem a brecha entre o que as pessoas realmente desejam ou precisam e os resultados. Daí nascem disciplinas como o design participativo, o co-design, o design anthropology, etc., que buscam criar práticas mais democráticas, e que desmitificam a figura clarividente do designer, quebrando a visão modernista do design.

Fica claro que para entender as cidades é preciso olhar para estas complexidades que estão fora do plano, ainda mais em países como o Brasil onde há diferentes tipos de desenvolvimento, como disse Aloísio, e onde há grandes desigualdades socioeconômicas. Sabendo que o espaço público é usado de outras formas, diferentes das que foram planejadas, como fazer um projeto que corresponda a estas situações? Os métodos que existem estão dando bons resultados? Estão os cidadãos pedindo outra forma de espaço público?

\section{REFERÊNCIAS}

ARAVENA, Alejandro. 2014. My architectural philosophy? Bring the community into the process. Disponível em:

http://www.ted.com/talks/alejandro_aravena_my_architectural_philosophy_bring_th e_community_into_the_process Acesso em: 19 de janeiro de 2016.

CAMPBELL, Brígida. TERÇA-NADA, Marcelo. Intervalo, respiro, pequenos deslocamentos. Ações poéticas do Poro. São Paulo: Radical Livros, 2011.

CAVALCANTI, Lauro. Brasília: a construção de um exemplo. In: Arcos, v.1, n. único. Rio de Janeiro: PPDESDI/UERJ, Contra-Capa, out. 1998, p. 50-62.

SCHILLER, Beatriz. Importar tecnologia sem virar cidadão de segunda classe. In: LEITE, João de Souza (org.) Encontros: Aloísio Magahães. Rio de Janeiro: Azougue, 2015, p. 92-99.

JACQUES, Paola B. Cenografias e corpografias urbanas: Espetáculo e experiencia na cidade contemporânea. In: Revista Observatório Itau Cultural, n.5, (abr/jun. 2008). São Paulo, SP: Itaú Cultural, 2008, p. 49-58.

JACQUES, Paola B. Elogio aos Errantes. Salvador: editora UFBA, 2012.

JACQUES, Paola B. Estética da Ginga: a arquitetura das favelas através da obra de Hélio Oiticica. Rio de Janeiro: Casa da Palavra, 2007.

NEGRI, Antonio. Dispositivo metrópole. A multidão e a metrópole. In: Revista Lugar Comum, n. 25-26, maio-dezembro 2008, p. 201-208.

SMITH, Keri. The Guerilla Art Kit. Princeton Architectural Press, 2007. 